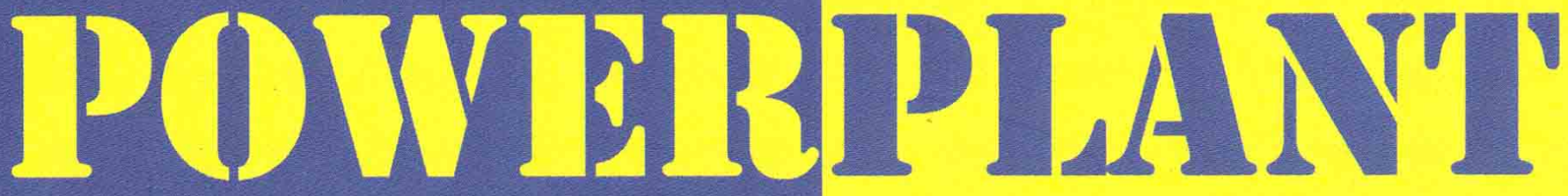

Nofirman:

Yusuf Rasyid

Vendy Antono;

Win Alfalah;

Rizky Windani

Eko Sulistiyo:

Utami Wahyuningsih:

M. Arif Rahman Sutisna

Sahlan

Vendy Antono;

Arief Suardi Nur Chairat;

Muhammad Husnuddin

Prayudi:

Roswati Nurhasanah

Hendri;

Suhengki:

Amru Fathony Lubis

Sri Yayi:

Jumiati;

Intan Ratna Sari Yanti
Pengaruh Kegagalan Terhadap Kinerja Chiller

Analisa Kegagalan Platen Tube SUperheater PLTU Teluk Sirih

Analisis Head Losses Pada Penstok Unit III Di Perum Jasa Tirta II Unit Jasa Pembangkit PLTA Ir. H.Djuanda

Kajian Terkait Industri Material HANKAM Dan

Kebencanaan Dari Sisi Pasar

Analisa Kerusakan Roda Gigi Cacing Pada Gearbox Air Preheater PLTU UJP Banten 3 Lontar Unit 1

Studi Eksperimental Kinerja Clod Strorage Mini dengan Refrigerant R2 dan R404A

Pengaruh Fouling Terhadap Laju Perpindahan Panas Pada Superheater Boiler CFB PLTU Sebalang

Pengaruh Jenis Pengetahuan Dan Kecakapan Terhadap Kemampuan Menulis Bahasa Inggris Pada Mahasiswa Teknik Mesin Sekolah Tinggi Teknik PLN

\begin{tabular}{|c|c|c|c|c|c|c|}
\hline$\|\mid\|$ & & SE & DLAH & VGGI TEKI & PLA & \\
\hline
\end{tabular}




\title{
PENGARUH FOULING TERHADAP LAJU PERPINDAHAN PANAS PADA SUPERHEATER BOILER CFB PLTU SEBALANG
}

\author{
Hendri $^{1, a^{*}}$, Suhengki ${ }^{2, b}$, dan Amru Fathony Lubis ${ }^{3}$ \\ 1,2,3 Jurusan Teknik Mesin STT- PLN Menara PLN J1 Lingkar Luar Barat Duri Kosambi \\ Cengkareng Jakarta Barat Indonesia, 11750 \\ ahendri@sttpln.ac.id, buhengki@yahoo.co.id
}

\begin{abstract}
Salah satu unit yang paling penting dalam produksi uap pada PLTU adalah boiler. Salah satu boileh jenis PLTU sering digunakan adalah boiler tipe CFB (Circulating Fluidized Bed), dan jenis bahan bakar batu bara yang digunakan banyak mengandung zat basa. Superheater merupakan salah satu komponen terpenting pada boiler. Superheater berfungsi untuk memanaskan uap agar kandungan energi panas dan kekeringannya bertambah sehingga menjadi uap superheat. Permasalahan yang sering terjadi pada superheater yaitu penumpukan abu (fouling) yang terjadi pada tube superheater tersebut. Unsur yang paling berpengaruh pada fouling adalah material basa terutama kadar $\mathrm{Na}_{2} \mathrm{O}$. Bila kadar abu batubara banyak, kemudian unsur basa dalam abu juga banyak, ditambah kadar $\mathrm{Na}_{2} \mathrm{O}$ yang tinggi, maka fouling akan mudah terjadi. Kadar sulfur yang tinggi cenderung mendorong timbulnya fouling. Fouling dapat menyebabkan penurunan laju perpindahan panas antara flue gas dengan steam pada superheater. Potensi fouling dapat diukur menggunakan suatu persamaan, tetapi persamaan tersebut hanya memperhitungkan chemical composition dari batubara tersebut. Dari penelitian diperoleh hasil terjadi penurunan laju perpindahan panas untuk high temperature superheater dari sootblowing satu ke sootblowing selanjutnya sebesar 511,8458 kW atau sekitar 3,012\%. Sedangkan penurunan laju perpindahan panas untuk low temperature superheater dari sootblowing satu ke sootblowing selanjutnya sebesar 3421,506 kW atau sekitar 13,028\%. Unsur yang paling berpengaruh pada fouling adalah material basa terutama $\mathrm{Na}$, yang dalam hal ini kadar $\mathrm{Na}_{2} \mathrm{O}$. Potensi terjadinya fouling yang dihitung dari data analisis fly ash menunjukkan nilai potensi fouling sebesar 4,0069 yang masuk dalam kategori potensi fouling tinggi pada fly ash lignit.
\end{abstract}

Keywords: superheater, fouling, fly ash,

\section{PENDAHULUAN}

PLTU Sebalang menggunakan boiler tipe CFB (Circulating Fluidized Bed). Pada boiler tipe CFB superheater terdapat pada heat recovery area atau backpass. Superheater digunakan sebagai pemanas lanjut uap agar uap tersebut menjadi uap kering. Pemanasan pada superheater diambil dari panas gas buang hasil pembakaran diruang pembakaran (furnace). Gangguan yang sering terjadi pada superheater khususnya final secondary superheater yaitu fouling. Fouling merupakan fenomena menempel dan menumpuknya abu pada dinding penghantar panas (super heater maupun re-heater) yang dipasang di lingkungan dimana suhu gas pada bagian belakang furnace lebih rendah dibandingkan suhu melunak abu (ash softening temperature). (Sumarno, dkk, 2014)
Peranan superheater pada power plant sangat vital. Apabila peformanya mengalami gangguan sehingga kinerjanya menurun, maka tingkat keadaan uap yang dihasilkan menjadi lebih rendah dan daya yang dihasilkan turbin menjadi rendah. Penurunan kinerja pada superheater tersebut disebabkan menurunnya efektifitas perpindahan panas dalam alat tersebut akibat terjadinya pengotoran permukaan (fouling) . Pada umumnya peranan kinerja alat tersebut di luar gangguan masalah teknik sistem mekanisnya, disebabkan oleh menurunkan efektivitas dan karakterisitik perpindahan panas di dalam alat yang terjadi pad superheater yang disebabkan oleh pengotoran permukaan pipa akibat proses pembakaran di dalam boiler, maupun pengotoran dalam pipa yang disebabken oleh aliran fluida (Sugiarto, 2011). 
Efektifitas penggunaan bahan bakar fosil untuk pembangkit tenaga bergantung dari kemampuan peralatan pembangkit uap untuk mengakomodasi sisa pembakaran tak aktif yang umumnya disebut ash (abu). Kuantitas dan karakteristik dari ash tidak dapat dipisahkan dari bahan bakar yang merupakan perhatian utama dari desain dan operasi dari peralatan pembangkit listrik. Pada umumnya bahan bakar komersial mengandung sejumlah ash yang menjadi pertimbangan dalam desain dan operasi yang spesifik. Ash akan menurunkan nilai kalor bahan bakar dan membuat fuel storage menjadi berat, maka diperlukan peralatan yang besar untuk mengumpulkan dan memindahkan ash. Dalam boiler pembakaran batu bara pulverized, umumnya ash batubara terbawa ke furnace oleh produk gas hasil pembakaran (flue gas). Partikel gas yang terbawa dalam aliran gas dapat menimbulkan masalah erosi dan korosi pada permukaan yang dilalui panas konveksi. Namun, masalah utama dari ash adalah endapannya. Endapan inilah yang menyebabkan terjadinya fouling pada pipa boiler.(Amaliyah, 2011).

Fouling sudah menjadi masalah sejak alat penukar kalor ditemukan. Fouling dapat didefinisikan sebagai pembentukan lapisan deposit pada permukaan perpindahan panas dari suatu bahan atau senyawa yang tidak diinginkan. Pembentukan lapisan deposit ini akan terus berkembang selama alat penukar kalor dioperasikan. Akumulasi deposit pada permukaan alat penukar kalor menimbulkan kenaikan pressure dropdan menurunkan efisiensi perpindahan panas. Untuk menghindari penurunan performancealat penukar kalor yang terus berlanjut dan terjadinya unpredictable cleaning, maka diperlukan suatu informasi yang jelas tentang tingkat pengotoran untuk menentukan jadwal pembersihan (cleaning schedule). Keterlibatan beberapa faktor diantaranya jenis alat penukar kalor, jenis material yang dipergunakan dan fluida kerja : jenis fluida, temperatur fluida, laju alir masa, jenis dan konsentrasi kotoran yang ada dalam fluida, dll., menjadikan fouling suatu masalah yang sangat kompleks, sehingga dalam melakukan pengukuran tingkat pengotoran ini menjadi sulit, oleh karena itu diperlukan suatu teknik analisa yang dapat mempermudah dan mempercepat pengukuran tersebut, diharapkan dengan bantuan teori bilangan tak berdimensi kesukaran pengukuran ini dapat dikurangi. (Sunandar, 2003)

Sebelumnya sudah ada penelitian yang membahas masalah fouiling, diantaranya menyimpulkan bahwa ada suatu korelasi inier antara besarnya faktor pengotoran $\mathrm{Rf}$ dengan bilangan tak berdimensi Ks, sehingga bilangan Ks dapat dipakai untuk menentukan besarnya faktor pegotoran, dan nilai Rf berkisar anra nol dan satu (Sunandar, 2003). Sedangkan dari sisi komposisi bahan bakar batu bara diperoleh hasil bahwa analisis ash dan ash Fusion Temperature, terlihat bahwa batu bara campuran diklasifikasikan sebagai ash lignit dengan potensi slagging yang rendah $(\mathrm{Rs}=2735,6)$ dan potensi fouling yang rendah-sedang $(\mathrm{Rf}=0,25)$. (Amaliyah, 2011). Sedangkan unsur yang paling berpengaruh pada fouling adalah adalah material basa terutama $\mathrm{Na}$, yang dalam hal ini kadar Na2O. Bila kadar abu batubara banyak, kemudian unsur basa dalam abu juga banyak, ditambah kadar $\mathrm{Na} 2 \mathrm{O}$ yang tinggi, maka fouling akan mudah terjadi. Indeks fouling yang dihitung dari data analisis batubara pada pasokan tanggal 1 November 2013 menunjukkan nilai $\mathrm{Rf}=0,346$ yang masuk dalam kategori indeks fouling medium pada ash bitominous. Fouling akan berpengaruh pada proses perpindahan panas yang terjadi pada final secondary superheater antara steam dan flue gas (Sumarno, 2014). Faktor pengotoran ini menjadi penyebab utma mengapa alat super hetaer yang digunakan pada instalasi pembangkit listrik harus mengalami cleaning.

Dari studi pustaka belum ada riset yang membahas pengaruh fouling terhadap karakteristik perpindahan panas pada peralatan superheater di pembangkit. Oleh karena itu pada kesempatan ini diajukan proposal penelitian yang berjudul "Pengaruh Fouling Terhadap Karakteristik Perpindahan Panas Pada Superheater Boiler Jenis CFB" Metode penelitian yang digunakan adalah metode deskriptif, dan data-data yang digunakan adalah adalah hasil operasi dan pengujian PLTU Sebalang pada tahun 2017.

\section{TINJAUAN PUSTAKA}

Fouling adalah fenomena menempel dan menumpuknya abu batu bara yang melebur pada pipa penghantar panas (heat exchanger tube) ataupun dinding boiler. Kedua hal ini sangat serius karena dapat memberikan dampak yang besar pada operasional boiler, seperti masalah 
penghantaran panas, penurunan efisiensi boiler, tersumbatnya pipa, serta kerusakan pipa akibat terlepasnya clinker. Fenomena menempelnya abu ini terutama dipengaruhi oleh suhu melebur abu AFT (Ash Fusion Temperature), dan unsur - unsur dalam abu. Selain kedua faktor tadi, evaluasi terhadap masalah ini juga dapat diketahui melalui perhitungan rasio terhadap beberapa unsur tertentu dalam abu. Fouling merupakan fenomena menempel dan menumpuknya abu pada dinding penghantar panas yang dipasang di lingkungan dimana suhu gas pada bagian belakang furnace lebih rendah dibandingkan suhu melunak abu (ash softening temperature).

Unsur yang paling berpengaruh pada penempelan abu ini adalah material basa terutama $\mathrm{Na}$, yang dalam hal ini adalah kadar $\mathrm{Na}_{2} \mathrm{O}$. Bila kadar abu batubara banyak, kemudian unsur basa dalam abu juga banyak, ditambah kadar $\mathrm{Na}_{2} \mathrm{O}$ yang tinggi, maka fouling akan mudah terjadi. Evaluasi karakteristik fouling sama dengan untuk slagging, yaitu dinilai berdasarkan rasio unsur basa dan asam, serta kadar $\mathrm{Na}_{2} \mathrm{O}$ di dalam abu. Jika nilai - nilai tadi tinggi, maka secara umum kecenderungan fouling juga meningkat. Selanjutnya, kadar sulfur yang tinggi juga cenderung mendorong timbulnya fouling melalui pembentukan senyawa bersuhu lebur rendah, melalui persenyawaan dengan unsur basa ataupun besi.

Berdasarkan proses terbentuknya endapan atau kotoran, faktor pengotoran dibagi lima jenis, yaitu :

1) Pengotoran akibat pengendapan zat padat dalam larutan (precipitation fouling). Pengotoran ini biasanya terjadi pada fluida yang mengandung garam-garam yang terendapkan pada suhu tinggi, seperti garam kalsium sulfat, dll.

2) Penegotoran akibat pengendapan partikel padat dalam fluida (particulate fouling). Pengotoran ini terjadi akibat pengumpulan partikel-partikel padat yang terbawa oleh fluida di atas permukaan perpindahan panas, seperti debu, pasir, dll.

3) Pengotoran akibat reaksi kimia (chemical reaction fouling). Pengotoran terjadi akibat reaksi kimia didalam fluida, diatas permukaan perpindahan panas, dimana material bahan permukaan perpindahan panas tidak ikut bereaksi, seperti adanya reaksi polimerisasi, dll.

4) Pengotoran akibat korosi (corrosion fouling). Pengotoran terjadi akibat reaksi kimia antara fluida kerja dengan material bahan permukaan perpindahan panas.

5) Pengotoran akibat aktifitas biologi (biological fouling). Pengotoran ini berhubungan dengan akitifitas organisme biologi yang terdapat atau terbawa dalam aliran fluida seperti lumut, jamur, dll.

Untuk menulai indeks fouiling yang menempel pada abu tergantung pada kadar dari $\mathrm{Na} 2 \mathrm{O}$ dan tergantung dari jenis baru baranya. Berikut ini akan dijelaskan beberapa cara penilaian terhadap fouling.

\section{Metode Evaluasi Representatif}

Sebagaimana dijelaskan sebelumnya bahwa faktor utama yang mempengaruhi kondisi menempelnya abu adalah $\mathrm{Na}_{2} \mathrm{O}$. Oleh karena itu, perusahaan $\mathrm{B} \& \mathrm{~W}$ menentukan penilaian fouling berdasarkan persamaan di bawah ini.

(a). Untuk pembagian tipe abu juga sama dengan untuk slagging.

Abu tipe bituminus $\left(\mathrm{CaO}+\mathrm{MgO}<\mathrm{Fe}_{2} \mathrm{O}_{3}\right)$ Indeks fouling untuk ash bituminous didapatkan dari karakteristik kekuatan sintering menggunakan kandungan sodium $\left(\mathrm{Fe}_{2} \mathrm{O}_{3}, \mathrm{CaO}\right.$, $\mathrm{MgO}, \mathrm{Na}_{2} \mathrm{O}, \mathrm{K}_{2} \mathrm{O}$ ) dari ash batubara dan rasio dasar dari asam $\left(\mathrm{SiO}_{2}, \mathrm{Al}_{2} \mathrm{O}_{3}, \mathrm{TiO}_{2}\right)$ :

$$
\mathrm{Rf}=\frac{\left(\mathrm{Fe}_{2} \mathrm{O}_{3}+\mathrm{CaO}+\mathrm{MgO}+\mathrm{Na}_{2} \mathrm{O}+\mathrm{K}_{2} \mathrm{O}\right)}{\left(\mathrm{SiO}_{2}+\mathrm{Al}_{2} \mathrm{O}_{3}+\mathrm{TiO}_{2}\right)} \times \mathrm{Na}_{2} \mathrm{O}
$$

Tabel 1. Standar NilaiIndeks Fouling Bituminius

\begin{tabular}{|c|c|}
\hline Potensi fouling & Nilai RF \\
\hline Low & $0.2<$ \\
\hline Medium & $0.2 \sim 0.5$ \\
\hline High & $0.5 \sim 1.0$ \\
\hline Severe & $>1.0$ \\
\hline
\end{tabular}

(b). Abu tipe lignit $\left(\mathrm{CaO}+\mathrm{MgO}>\mathrm{Fe}_{2} \mathrm{O}_{3}\right)$

Klasifikasi fouling untuk ash batubara lignit adalah berdasarkan kandungan sodium dalam ash sebagai berikut :

$$
\mathrm{Rf}=\text { kadar } \mathrm{Na}_{2} \mathrm{O}(\%)
$$

Tabel 2. Standar Nilai Abu Type Lignit

\begin{tabular}{|c|c|}
\hline Potensi fouling & Nilai Rf \\
\hline Low & $1.2<$ \\
\hline Medium & $1.2 \sim 3.0$ \\
\hline High & $3.0 \sim 6.0$ \\
\hline Severe & $>6.0$ \\
\hline
\end{tabular}


Tingkat fouling pada penukar kalor dihitung dengan rumus,

$$
R_{f}=R_{f}^{*}\left(1-e^{-t / t_{c}}\right)
$$

dimana tc adwal waktu. Karena tahanan termal fouling dapat juga didefinisikan dengan rumus,

$$
R_{f}=\frac{1}{U_{f}}-\frac{1}{U_{c}}
$$

dimana $U_{f}$ dan $U_{C}$ adalah koefisien perpindahan panas menyeluruh pada kondisi tanpa fauling dan dengan fouling. Koefisien perpindahan panas menyeluruh dapat dihitung dari persamaan,

$$
q=U A \Delta T_{L M T D}
$$

dimana A adalah luas perpindahan panas, dan overall heat transfer dihitung dengan persamaan,

$\frac{1}{U}=\frac{A_{o}}{A_{i} h_{i}}+\frac{A_{o}}{A_{i}} R_{f i}+\frac{A_{o} \ln \left(d_{o} / d_{i}\right)}{2 \pi k l}+R_{f o}+\frac{1}{h_{o}}$

Koefisien konveksi pada sisi dalam dan luar tube pada rumus (6) dihitung dengan persamaan,

$$
h_{i}=\frac{\mathrm{Nu}_{i} k_{i}}{d_{i}}
$$

dan

$$
h_{o}=\frac{\mathrm{Nu}_{o} k_{o}}{d_{o}}
$$

dimana ko dan ki pada persamaan (7) dan (8) masing-masing adalah konduktivtas termal fluida panas dan dingin. $\mathrm{Nu}$ pada persamaan (7) dan (8) dihitung dengan rumus, Dittus and Boelter,

$$
N u=0.023 \operatorname{Re}^{0.8} \operatorname{Pr}^{n}
$$

Untuk Re $>500$ and $07<\operatorname{Pr}<150$, dimana $\mathrm{n}=0,4$ untuk pemenasan dan and 0.3 untuk pendinginan. Sedangkan perbedaan panas $\Delta T_{L M T D}$ pada persamaan (5) dihitung dengan rumus,

$$
\Delta T_{L M T D}=\frac{\left(\mathrm{T}_{\mathrm{i}, 1}-\mathrm{T}_{\mathrm{o}, 2}\right)-\left(\mathrm{T}_{\mathrm{o}, 1}-\mathrm{T}_{\mathrm{i}, 2}\right)}{\ln \left\{\left(\mathrm{T}_{\mathrm{i}, 1}-\mathrm{T}_{\mathrm{o}, 2}\right) /\left(\mathrm{T}_{\mathrm{o}, 1}-\mathrm{T}_{\mathrm{i}, 2}\right)\right\}}(10)
$$

Efektivitas perpindahan panas pada alat penukar kalor dampak fouling untuk aliran cross flow single phase dihitung dengan rumus, $\varepsilon=1-\exp \left\{\frac{\mathrm{NTU}^{0.22}}{\mathrm{C}}\left[\exp \left(-\mathrm{C} \mathrm{NTU}^{0.78}\right)-1\right]\right\}$

\section{METODOLOGI PENELITIAN}

Untuk mempermudah di dalam penyelesaian masalah penelitian tentang pengaruh fouling terhadap laju perpindahan panas pada superheater boiler CFB ada PLTU Sebalang sebagai objyek peneltian seperti terlihat pada gambar,

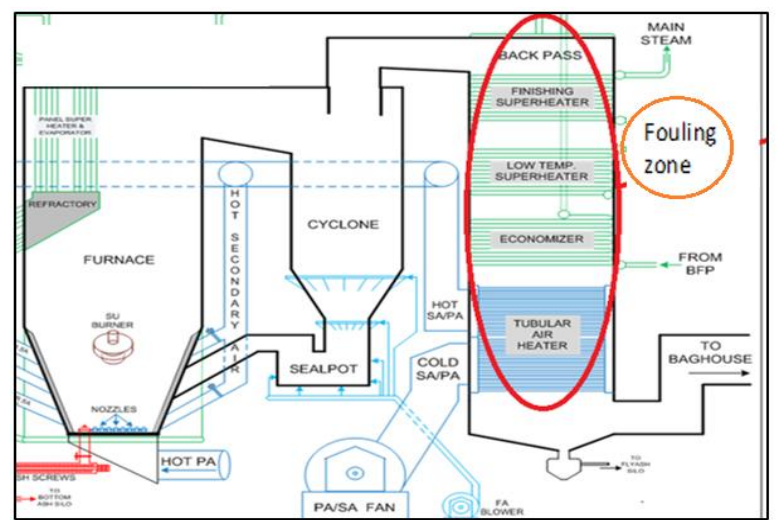

Gambar 1. Lokasi Pengampilan Sampel Penelitian

Spesifikasi penukar kalor high temperature superheater diamater luar tube $0.042 \mathrm{~m}$, inside diameter tube $0.031 \mathrm{~m}$. luas permukaan luar pipa $1789 \mathrm{~m} 2$, trabsverse spacing $0,1 \mathrm{~m}$, longtunidal spacing $0,07913 \mathrm{~m}$, jumlah tube 110 , materiala tube 12Cr1MoVG/T91. Sedangan spesifikasi penukar kalor pada low temperature superheater diamater luar tube $0.042 \mathrm{~m}$, inside diameter tube $0.031 \mathrm{~m}$. luas permukaan luar pipa $3608 \mathrm{~m}^{2}$, transverse spacing $0,1 \mathrm{~m}$, longtudinal spacing $0,07217 \mathrm{~m}$, jumlah tube 110 , material tube 20G/15CrMoG. Penghitungan sifat-sifat fluida nilai entalpi, massa jenis, panas jenis, viskotas dinamis, dan konduktivitas termal menggunakan aplikasi software steam tab versi 2.1

Data-data operasi yang digunakan pada high temperatur superheater disajikan pada tabel 3. Low temperatur disajikan pada tabel 4. Sampel diambil pada bulan Maret 2017

Tabel 3.

\begin{tabular}{|l|l|l|l|l|l|}
\hline Parameter & Sampel 1 & Sampel 2 & Sampel 3 & Sampel 4 & Sampel 5 \\
\hline Temperatur uap masuk $\left({ }^{\circ} \mathrm{C}\right)$ & 454.7 & 453.3 & 450.4 & 447.2 & 444.2 \\
\hline Temperatur uap keluar $\left({ }^{\circ} \mathrm{C}\right)$ & 546.6 & 544.4 & 541.0 & 538.2 & 535.9 \\
\hline Temperatur gas masuk $\left({ }^{\circ} \mathrm{C}\right)$ & 692.3 & 697.1 & 705.3 & 713.0 & 719.1 \\
\hline Temperatur gas keluar $\left({ }^{\circ} \mathrm{C}\right)$ & 574.4 & 580.2 & 588.3 & 592.9 & 602.9 \\
\hline Aliran massa uap $(\mathrm{kg} / \mathrm{s})$ & 76.03 & 75.83 & 75.79 & 75.02 & 73.87 \\
\hline Tenakan uap (bar) & 71.17 & 70.54 & 70.09 & 69.48 & 68.83 \\
\hline
\end{tabular}


Tabel 4.

\begin{tabular}{|l|l|l|l|l|l|}
\hline Parameter & Sampel 1 & Sampel 2 & Sampel 3 & Sampel 4 & Sampel 5 \\
\hline Temperatur uap masuk $\left({ }^{\circ} \mathrm{C}\right)$ & 305.8 & 302.8 & 298.9 & 293.5 & 289.3 \\
\hline Temperatur uap keluar $\left({ }^{\circ} \mathrm{C}\right)$ & 420.6 & 410.8 & 401.5 & 392.3 & 382.9 \\
\hline Temperatur gas masuk $\left({ }^{\circ} \mathrm{C}\right)$ & 574.4 & 580.2 & 588.3 & 595.9 & 602.9 \\
\hline Temperatur gas keluar $\left({ }^{\circ} \mathrm{C}\right)$ & 420.2 & 431.5 & 442.9 & 455.2 & 468.2 \\
\hline Aliran massa uap $(\mathrm{kh} / \mathrm{s})$ & 76.03 & 75.83 & 75.79 & 75.02 & 73.87 \\
\hline Tenakan uap (bar) & 71.17 & 70.54 & 70.09 & 69.48 & 68.83 \\
\hline
\end{tabular}

\section{HASIL DAN PEMBAHASAN}

\subsection{Potensi Fouling Pada Superheater}

Pengujian Charactirization Fouling Deposits menggunakan standar ASTM D36822013 dan ASTM D5016-2008. Data komposisi kimia belum disajikan tabel 5 .

Tabel 5. Hasil uji komposisi kimia pada abu fly ash,

\begin{tabular}{|c|c|c|c|}
\hline $\begin{array}{l}\text { Limestone } \\
\text { sample }\end{array}$ & $\begin{array}{l}\text { Bottom } \\
\text { ash }\end{array}$ & $\begin{array}{l}\text { Fly } \\
\text { ash }\end{array}$ & $\begin{array}{l}\text { Inert } \\
\text { bed }\end{array}$ \\
\hline $\mathrm{SiO}_{2}(\% \mathrm{wt})$ & 67.10 & 37.20 & 66.80 \\
\hline $\mathrm{Al}_{2} \mathrm{O}_{3}(\% \mathrm{wt})$ & 13.00 & 15.25 & 13.20 \\
\hline $\mathrm{Fe}_{2} \mathrm{O}_{3}(\% \mathrm{wt})$ & 8.15 & 14.40 & 8.50 \\
\hline $\mathrm{CaO}$ (\% wt) & 3.88 & 15.90 & 6.62 \\
\hline $\mathrm{MgO}(\% \mathrm{wt})$ & 1.64 & 8.30 & 2.14 \\
\hline $\mathrm{TiO}_{2}(\% \mathrm{wt})$ & 0.49 & 0.56 & 0.57 \\
\hline $\mathrm{Na}_{2} \mathrm{O}(\% \mathrm{wt})$ & 4.25 & 4.13 & 0.88 \\
\hline $\mathrm{K} 2 \mathrm{O}(\% \mathrm{wt})$ & 0.92 & 0.70 & 0.79 \\
\hline $\mathrm{Mn}_{3} \mathrm{O}_{4}(\% \mathrm{wt})$ & 0.185 & 0.505 & 0.208 \\
\hline $\mathrm{P}_{2} \mathrm{O}_{5}(\% \mathrm{wt})$ & 0.138 & 0.146 & 0.120 \\
\hline $\mathrm{SO}_{3}(\% \mathrm{wt})$ & 0.10 & 2.78 & 0.10 \\
\hline
\end{tabular}

Faly ash merupakan abu yang berpotensi menempel pada dinding tube superheter. Berdasarkan hasil analisis proximate nilai kalori pada PLTU Sebalang adalah $4185,1 \mathrm{kcal} / \mathrm{kg}$ atau $17577,42 \mathrm{~kJ} / \mathrm{kg}$, dan type batubara sesuai tabel 1 adalah batubara tipe bituminous. Potensi fouling digunakan karakteristik kekuatan sintering menggunakan kandungan sodium $\left(\mathrm{Fe}_{2} \mathrm{O}_{3}, \mathrm{CaO}\right.$, $\mathrm{MgO}, \mathrm{Na}_{2} \mathrm{O}, \mathrm{K}_{2} \mathrm{O}$ ) dari ash batubara dan rasio dasar dari asam $\left(\mathrm{SiO}_{2}, \mathrm{Al}_{2} \mathrm{O}_{3}, \mathrm{TiO}_{2}\right)$. Mengacu pada base to acid index (eq. 1 ), $\mathrm{B} / \mathrm{A}=0.82$, the tendency toward sedimentation is low, and base slagging $S_{R}=48.53 \%$ include categories high slagging, and fouling index, $\mathrm{Fu}=3.97$ termasuk high fouling. Kontribusi dari alkali khususnya $\mathrm{Na}_{2} \mathrm{O}$ juga menunjukkan ada potensi munculnya fouling. Karena bentuk cair dari elemen alkali ini akan menguap dalam furnace pada saat temperatur pembakaran dan juga dapat bereaksi dengan sulfur dan elemen abu lainnya membentuk suatu ikatan yang memberikan kontribusi untuk terjadinya fouling di daerah konveksi. Nilai kalori dari batubara berdampak pada potensi timbulnnya fouling, semakin besar nilai kalori batubara yang digunakan akan berdampak kecil pada potensi timbulnya fouling.

Jenis material yang dipakai untuk tube sebagai media dalam heat exchanger ini adalah Heat Resistant Alloy (12Cr1MoVG/T91 dan 20G/15CrMoG) merupakan bahan yang cukup kuat untuk menahan temperature kerja yang tinggi. Kandungan chromium berfungsi menambah wear resistance sehingga kemungkinan terjadinya erosi dikarenakan korosi dan fouling juga semakin rendah. Kandungan molybdenum mencegah kerapuhan dan menjaga kekuatan baja pada suhu tinggi. PLTU dengan tipe boiler CFB menggunakan bahan bakar batubara. Batubara yang dibakar menyisakan abu, abu yang cukup ringan (fly ash) akan terbawa oleh flue gas dan menempel pada pipa-pipa pemanas pada heat recovery area/backpass.

Penanganan fouling yang terjadi pada superheater dapat diatasi salah satunya dengan menggunakan sootblower. Jika dilihat kembali pada tabel, standar nilai abu tipe lignit 3,0-6,0 merupakan potensi fouling yang tinggi, sehingga potensi pembentukan fouling untuk nilai 4,0069 dapat dikategorikan cukup tinggi. Juga kontribusi dari alkali khususnya $\mathrm{Na}_{2} \mathrm{O}$ juga menunjukkan ada potensi munculnya fouling. Karena bentuk cair dari elemen alkali ini akan menguap dalam furnace pada saat temperatur pembakaran dan juga dapat bereaksi dengan sulfur dan elemen abu lainnya membentuk suatu ikatan yang memberikan kontribusi untuk terjadinya fouling di daerah konveksi.

\subsection{Peningkatan Faktor Fouling Pada Superheater \\ Berikut adalah grafik faktor fouling pada kondisi operasi superheater.}




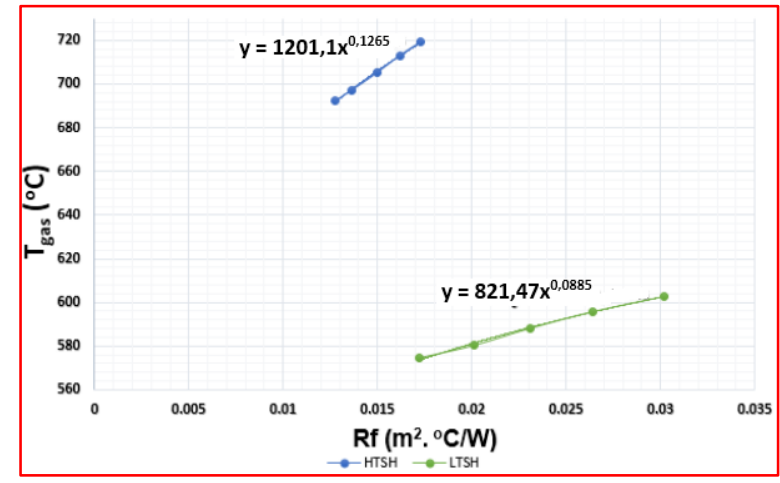

Gambar 2. Faktor fouling pada superheater

Untuk high temperature superheater ratarata peningkatan tahanan termal akibat fouling pada tiap sampel sekitar $0,001128 \mathrm{~m}^{2} .{ }^{\circ} \mathrm{C} / \mathrm{W}$ atau sekitar $7,87 \%$ membentuk persamaan $\mathrm{y}=1201,1 \mathrm{x}^{0,1265}$. Sedangkan untuk low temperature superheater rata-rata peningkatan tahanan termal akibat fouling pada tiap sampel sekitar $0,003238 \mathrm{~m}^{2} .{ }^{\circ} \mathrm{C} / \mathrm{W}$ atau sekitar $15,06 \%$ membentuk persamaan $\mathrm{y}=821,47 \mathrm{x}^{0,0885}$. Kedua superheater tersebut tidak bisa dibandingkan begitu saja dikarenakan perbedaan desain dan kondisi operasinya. Akan tetapi dari gambar di atas terlihat bahwa terjadi peningkatan harga tahanan termal lapisan fouling pada high temperature superheater lebih besar dari pada pertumbuhan fouling pada low temperature superheater, hal tersebut bisa dilihat dari koefisien (gradien) dua persamaan diatas.

Kondisi menumpuknya fouling biasa terjadi pada alat penukar kalor yang dirancang dengan menggunakan faktor fouling yang konstan yang diperoleh dari standar desainnya sebesar 0,0025 $\mathrm{m}^{2} .{ }^{\circ} \mathrm{C} / \mathrm{W}$, sehingga terjadilah kondisi yang tidak dapat dioperasikan sesuai dengan harga design pointnya pada saat alat tersebut mulai dioperasikan.

\subsection{Peningkatan Nilai LMTD Pada Superheater \\ Nilai LMTD (Logarithmic Mean} Temperature Difference) adalah nilai yang berkaitan dengan perbedaan temperatur antara sisi panas dan sisi dingin penukar panas ${ }^{[3]}$. Superheater difungsikan untuk meningkatkan kadar kekeringan uap dengan memanaskannya menggunakan flue gas. Tujuan perpindahan panas ini di dalam proses produksi adalah untuk memanaskan uap hingga mencapai temperatur tertentu yang diinginkan. Temperatur gas akan menurun setelah memanaskan uap, begitu pula dengan temperatur uap yang meningkat setelah dipanaskan oleh gas, kedua hal tersebut menunjukkan adanya transfer energi panas dari fluida panas (gas) ke fluida dingin (uap). Berikut adalah grafik nilai LMTD pada kondisi operasi superheater.

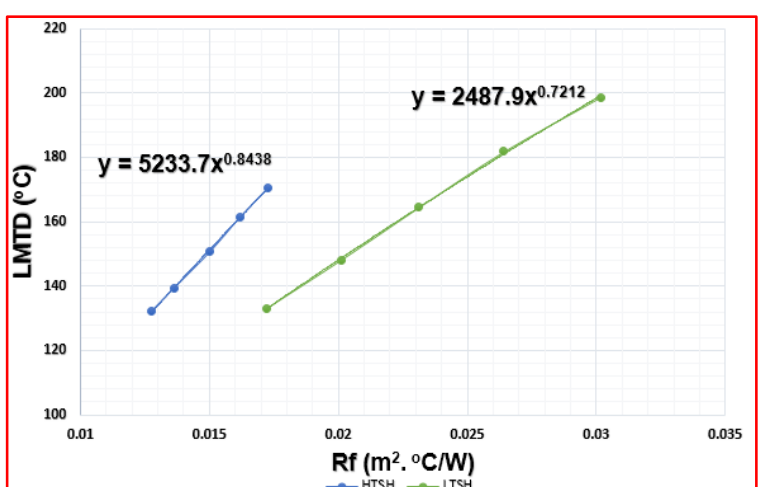

Gambar 3. Pengaruh fouling terhadap nilai LMTD

Dari grafik di atas dapat dilihat untuk high temperature superheater rata-rata mengalami peningkatan LMTD pada tiap sampel sekitar $6.58 \%$ atau sekitar $8,7{ }^{\circ} \mathrm{C}$, membentuk garis linier dengan persamaan $\mathrm{y}=5233,7 \mathrm{x}^{0,8438}$. Sedangkan untuk low temperature superheater rata-rata peningkatan LMTD pada tiap sampel sekitar $10,53 \%$ atau sekitar $14,01{ }^{\circ} \mathrm{C}$ membentuk garis linier dengan persamaan $\mathrm{y}=2487,9 \mathrm{x}^{0,7212}$.

Kedua persamaan diatas menunjukkan bahwa faktor fouling berbanding lurus dengan nilai LMTD. Perbedaan temperatur LMTD pada kedua superheater mengalami peningkatan. Hal ini menandakan perpindahan panas antara temperatur fluida panas (gas) dan temperatur fluida dingin (uap) tidak terserap dengan baik.

\subsection{Penurunan Koefisien Perpindahan Panas Menyeluruh}

Panas dialirkan secara konveksi dari fluida panas ke dinding pipa, kemudian panas dikonduksikan melalui dinding pipa dan dikonveksikan kembali dari dinding pipa ke fluida dingin pada sisi luar pipa. 


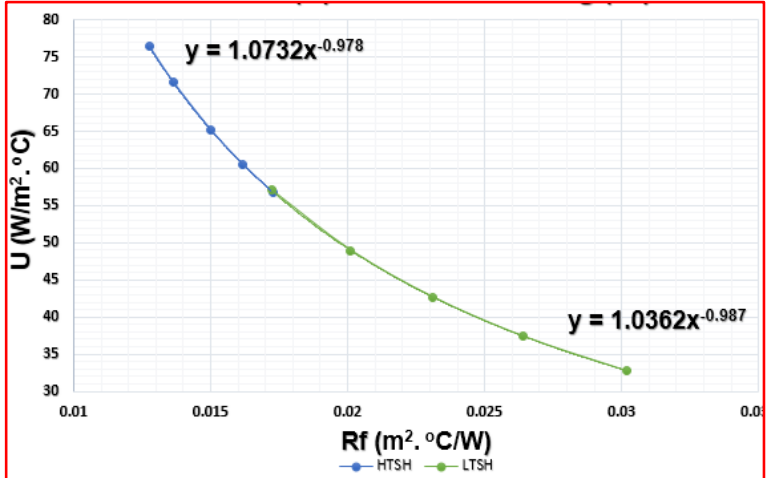

Gambar 4. Pengaruh fouling terhadap koefisien perpindahan panas global pada superheater

Dari grafik di atas dapat dilihat untuk high temperature superheater rata-rata mengalami penurunan koefisien perpindahan panas global pada tiap sampel sekitar 7,26\% atau sekitar 5,54 $\mathrm{W} / \mathrm{m}^{20} \mathrm{C}$, membentuk garis melengkung (curve) dengan $\mathrm{y}=1,0732 \mathrm{x}^{-0,978}$. Sedangkan untuk low temperature superheater rata-rata penurunan koefisien perpindahan panas global pada tiap sampel sekitar $12,88 \%$ atau sekitar $7,35 \mathrm{~W} / \mathrm{m}^{20} \mathrm{C}$ membentuk garis melengkung (curve) dengan persamaan $\mathrm{y}=1,0362 \mathrm{x}^{-0,987}$. Kedua persamaan diatas menunjukkan bahwa faktor fouling berbanding terbalik dengan koefisien perpindahan panas global. Penurunan koefisien perpindahan panas global pada high temperature superheater dan low temperature superheater akibat terjadi penurunan koefisien konveksi di dalam dan di luar pipa, hal tersebut disebabkan oleh menurunnya temperature uap di dalam pipa dan meningkatnya temperature gas di luar pipa dikarenakan perpindahan panas antara dua fluida tersebut terhambat oleh pertumbuhan fouling. Fouling yang terus tumbuh menambah tahanan termal dan menurunkan temperatur uap serta menghambat laju aliran gas.

\subsection{Perubahan Laju Perpindahan Panas Pada Superheater}

Mekanisme dari perpindahan panas yang terjadi pada boiler yaitu konveksi - konduksi konveksi. Untuk proses perpindahan panasnya pada boiler yaitu fly ash menyebar pada komponen superheater dan merambatkan panas melalui dinding komponen, kemudian perambatan panas tersebut masuk kedalam tube dari komponen superheater.

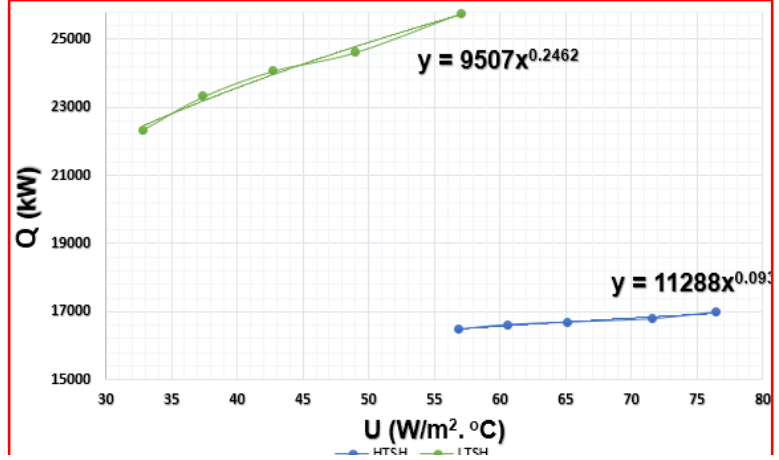

Gambar 5. Hubungan dan laju perpindahan panas superheater dan koefisien perpindahan panas global

Apabila nilai koefisien perpindahan panas global menurun maka menghasilkan nilai kalor uap yang rendah, apabila kalor penguapan rendah maka laju perpindahan panas pada superheater semakin kecil.

Apabila nilai perbedaan temperatur LMTD semakin tinggi artinya penyerapan gas buang ke dalam pipa terhalang hambatan-hambatan (fouling) dan perpindahan panas tidak maksimal, maka kalor uap yang dihasilkan rendah dan menurunkan laju perpindahan panas pada superheater.

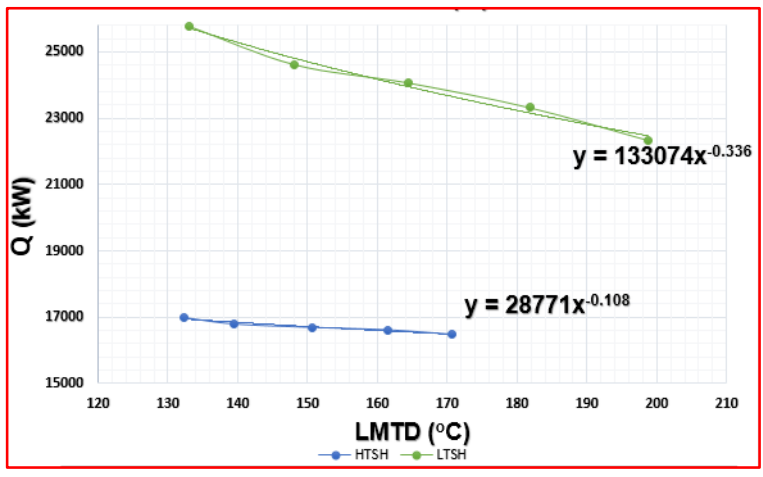

Gambar 6. Hubungan dan laju perpindahan panas superheater dan nilai LMTD

Untuk pengaruh faktor fouling terhadap laju perpindahan panas dapat dilihat pada grafik berikut. 


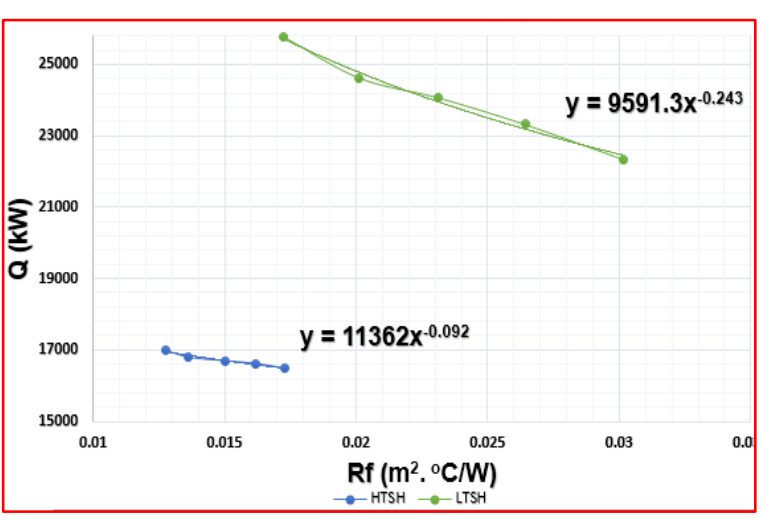

Gambar 7. Pengaruh fouling terhadap laju perpindahan panas superheater

Dari beberapa grafik di atas dapat dilihat bahwa terjadi penurunan laju perpindahan panas untuk high temperature superheater dari sootblowing satu ke sootblowing selanjutnya sebesar 511,8458 $\mathrm{kW}$ atau sekitar 3,012\%, membentuk persamaan $\mathrm{y}=11362 \mathrm{x}^{-0,092}$. Sedangkan penurunan laju perpindahan panas untuk low temperature superheater dari sootblowing satu ke sootblowing selanjutnya sebesar 3421,506 kW atau sekitar 13,028\%, persamaan $\mathrm{y}=9591,3 \mathrm{x}^{-0,243}$.

Dari beberapa grafik di atas dapat dilihat bahwa laju perpindahan panas pada superheater berbanding lurus dengan koefisien perpindahan panas global pada superheater dan berbanding terbalik dengan nilai LMTD dan faktor fouling superheater tersebut. Sehingga untuk penyebab penurunan pada laju perpindahan panas sama dengan penyebab penurunan koefisien perpindahan panas global dan penyebab peningkatan nilai LMTD. Pernyataaan di atas membuktikan persamaan $\mathrm{Q}=$ U.A.F.LMTD.

\subsection{Penurunan efektifitas superheater}

Secara umum nilai efektifitas $(\varepsilon)$ heat exchanger dapat didefinisikan sebagai perbandingan laju perpindahan panas aktual dengan laju perpindahan panas maksimum yang mungkin terjadi pada heat exchanger ${ }^{[3]}$. Nilai efektifitas superheater juga dapat dihitung menggunakan nilai NTU (Number of Heat Transfer Unit). Grafik berikut menunjukkan nilai efektifitas superheater.

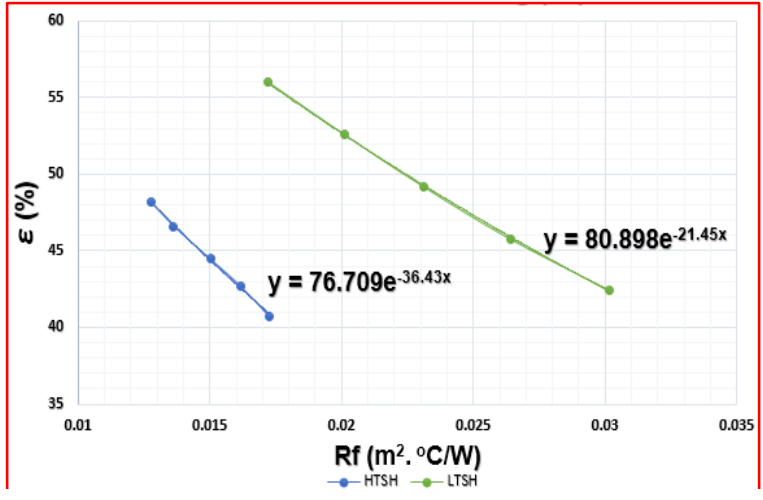

Gambar 8. Penurunan nilai efektifitas pada superheater

Grafik di atas menunjukkan efektifitas heat exchanger pada high temperature superheater dan low temperature superheater mengalami tren penurunan. Untuk high temperature superheater rata-rata penurunan efektifitas pada tiap sampel sekitar $1,6 \%$. Sedangkan untuk low temperature superheater rata-rata penurunan efektifitas tiap sampel sekitar 3,38\%. Kedua superheater tersebut tidak bisa dibandingkan begitu saja dikarenakan perbedaan desain dan kondisi operasinya. Dikarenakan mencari efektifitas superheater menggunakan NTU dan NTU berbanding lurus dengan koefisien perpindahan panas global, maka penyebabpenyebab penurunan pada koefisien perpindahan panas global juga menyebabkan penurunan efektifitas superheater. Apabila fouling menempel atau terbentuk pada permukaan pipa superheater maka akan mengganggu sistem karena dapat meningkatkan nilai resistifitas pada superheater.

Efisiensi pada boiler banyak dipengaruhi oleh proses perpindahan panas yang terjadi di dalamnya. Perpindahan panas pada boiler dapat ditingkatkan dengan melakukan pembersihan permukaan pipa dari abu-abu yang menempel. Pada superheater, fly ash yang merupakan hasil dari pembakaran akan menempel pada dindingdinding permukaan pipa.

Penanganan fouling yang terjadi pada superheater dapat diatasi salah satunya dengan menggunakan sootblower. Sootblower merupakan alat mekanik yang digunakan untuk membersihkan abu dan deposit secara periodik. Alat tersebut mengarahkan media pembersihan melalui nosel terhadap abu yang telah terakumulasi pada permukaan perpindahan panas dari boiler untuk mempertahankan efisiensi perpindahan panas. Pada superheater, sootblower yang digunakan bertipe long 
rectractable sootblower. Long rectractable sootblower dirancang untuk pembersihan yang efektif dari permukaan pemanas di zona suhu tinggi gas dari boiler dan penukar panas lainnya. Setiap sootblower dilengkapi dengan poppet valve untuk mengatur kebutuhan uap sootblower. Katup ini membuka pada saat sootblower dioperasikan dan menutup kembali saat lance tube dari sootblower tersebut mundur menuju stop. Steam yang digunakan pada sootblower menggunakan steam keluaran dari low temperature superheater dengan tekanan sebesar 10 bar.

Pada boiler CFB unit 1 PLTU Sebalang pengoperasian sootblower berdasarkan temperatur gas yang berada di dalam backpass yaitu tidak boleh melebihi $800{ }^{\circ} \mathrm{C}$. Jika temperatur di dalam backpass sangat tinggi akan berdampak pada material pipa-pipa superheater, struktur material akan berubah menyebabkan pipa-pipa melengkung atau bahkan pecah dikarenakan thermal shock. Thermal shock terjadi akibat ketidakmerataan temperatur pada pipa-pipa akibat timbulnya hotspot-hotspot dikarenakan penumpukan fouling.

Pencegahan fouling juga dapat dilakukan dengan merancang ulang mekanisme sootblowing yang semula secara manual menjadi otomatis berdasarkan kondisi (temperatur dan aliran flue gas) di dalam backpass. Sootblower tersebut dirancang agar beroperasi secara otomatis jika kondisi di dalam backpass sudah dipenuhi abu dan mengurangi secara signifikan laju perpindahan panas yang terjadi pada pipapipa pemanas. Untuk merancang mekanisme tersebut perlu adanya pengujian lebih lanjut dengan mengevaluasi pengaruh fouling terhadap laju perpindahan panas pada berbagai beban yang berbeda, sehingga dari evaluasi tersebut ditentukan standar yang tepat tentang kondisi di dalam backpass baik temperatur, tekanan, maupun aliran flue gas. Selanjutnya standar tersebut dijadikan pedoman perancangan mekanisme sootblowing secara otomatis. Mekanisme sooblowing secara otomatis tersebut dapat dilengkapi dengan alarm dan mengoptimalkan uap yang akan digunakan untuk blowing dengan pengaturan yang tepat pada peralatan seperti pressure control valve yang mengatur tekanan uap untuk sootblowing yang berasal dari low temperature superheater. Pemeliharan yang baik dan benar terhadap sootblower sangat berdampak pada kemampuan sootblower dalam membersihkan fouling pada backpass.
Kinerja sootblower yang buruk akan berdampak pada penurunan efektifitas superheater dikarenakan masih banyak fouling yang masih menempel dan tidak menutup kemungkinan fouling tersebut akan mengeras seiring dengan waktu operasi boiler. Untuk membersihkan fouling yang telah mengeras dapat dilakukan penjadwalan rutin dikarenakan fouling yang telah mengeras tidak dapat dibersihkan maksimal saat proses sootblowing.

\section{KESIMPULAN DAN SARAN}

\subsection{Kesimpulan}

Setelah melakukan pengujian pada superheater dan menganalisis fouling serta pengaruhnya superheater, penulis dapat menarik beberapa kesimpulan, yaitu:

1. Terjadi penurunan laju perpindahan panas untuk high temperature superheater dari sootblowing satu ke sootblowing selanjutnya sebesar $511,8458 \mathrm{~kW}$ atau sekitar 3,012\%, membentuk persamaan $\mathrm{y}=11362 \mathrm{x}^{-0,092}$. Sedangkan penurunan laju perpindahan panas untuk low temperature superheater dari sootblowing satu ke sootblowing selanjutnya sebesar 3421,506 $\mathrm{kW}$ atau sekitar 13,028\%, dengan persamaan $\mathrm{y}=9591,3 \mathrm{x}^{-0,243}$.

2. Unsur yang paling berpengaruh pada fouling adalah material basa terutama $\mathrm{Na}$, yang dalam hal ini kadar $\mathrm{Na}_{2} \mathrm{O}$. Bila kadar abu batubara banyak, kemudian unsur basa dalam abu juga banyak, ditambah kadar $\mathrm{Na}_{2} \mathrm{O}$ yang tinggi, maka fouling akan mudah terjadi.

3. Potensi terjadinya fouling yang dihitung dari data analisis fly ash menunjukkan nilai potensi fouling sebesar 4,0069 yang masuk dalam kategori potensi fouling tinggi pada fly ash lignit.

4. Terjadinya fouling akan berpengaruh pada proses perpindahan panas yang terjadi pada superheater antara uap dan flue gas. Dengan adanya penumpukan fly ash pada pipa superheater maka akan menghambat laju perpindahan panas yang terjadi superheater dan mengurangi produksi uap. Dengan adanya penumpukan fly ash juga akan menyebabkan timbulnya hotspot pada pipa-pipa superheater. Ketidakmerataan temperatur akibat adanya hotspot dapat menyebabkan thermal shock pada tube sehingga tube akan pecah. 


\subsection{Saran-saran}

Berdasarkan pengujian yang telah dilakukan dapat diketahui bahwa fouling menyebabkan beberapa kerugian. Dibutuhkan penanggulangan yang tepat terhadap fouling agar tidak menimbulkan masalah yang lebih serius.

1. Mekanisme sootblowing sebaiknya beroperasi secara otomatis berdasarkan kondisi di dalam backpass, dengan perancangan yang tepat agar pengoperasian sootblowing optimal dan meningkatkan laju perpindahan panas.

2. Evaluasi fouling sebaiknya dilakukan secara berkala dan disesuaikan dengan penggunaan batubara yang berasal dari berbagai daerah. Dari evaluasi fouling tersebut dapat ditentukan penggunaan batubara dari daerah mana dengan laju pertumbuhan fouling paling tinggi dan paling rendah. Sehingga untuk penggunaan batubara disarankan untuk menggunakan batubara dari daerah yang laju pertumbuhan fouling-nya paling rendah.

3. Evaluasi secara periodik terhadap kondisi operasi dapat mengungkap adanya keperluan untuk pembersihan atau mengubah kondisi operasi seperti model operasi, dan parameter kimia dari fluida, sehingga dapat ditentukan langkah-langkah penaggulangan dan pemeliharaan (cleaning) yang tepat.

\section{UCAPAN TERIMA KASIH}

Penelitian ini mendapatkan dana hibah internal STT-PLN untuk tahun anggaran 2017/2018, oleh karena itu Tim Peneliti mengucapkan kepada Ketua LPPM STT-PLN atas kepercayaan dan pendanaanya sehingga penelitian ini dapat terlaksana dengan baik.

\section{DAFTAR PUSTAKA}

[1] Amaliyah, Novriany. Analisis Komposisi Batubara Mutu Rendah Terhadap Pembentukan Slagging Dan Fouling Pada Boiler. Makassar, 2011.

[2] Andika Kurniawan, Ma'ruf . Jurnal Analisis Heat Transfer Pada Superheater PT. Indocement Tunggal Prakasa, Tbk. 2016

[3] Cengel A. Yunus. Heat Transfer A Practical Approach. Second Edition,
[4] Holman J.P. Perpindahan Kalor, diterjemahkan oleh Jasjfi: Erlangga, Jakarta,1997.

[5] Muranto, Dody. Analisis Pengaruh Fouling Terhadap Laju Perpindahan Panas Pada Economizer PLTU Tarahan. Jakarta, 2011.

[6] PLTU Sebalang, Tim. Mengenal PLTU CFB Sebalang 2x100 MW. Sebalang. 2016.

[7] Sadik Kakac \& Hongtan Liu. Heat Exchangers, Selection, Rating And Termal Design, Second Edition, 2002.

[8] Sunandar, Kudrat. Analisis Bilangan Tak Berdimensi Pada Proses Fouling Di Kondenser. Bogor, 2003.

[9] Tim CFB PT PLN (Persero) Pembangkitan Sumatera Bagian Selatan. Pengetahuan Terapan Mengelola Pembangkit PLTU CFB Menjadikan Pembangkit Kinerja Prima Dan Ramah Lingkungan. Palembang, 2015.

- Tris Sugiarto, Chandrasa Soekardi. Jurnal Analisis Kinerja Alat Superheater Pada Instalasi Pembangkit Tenaga Uap. 2015. 